Research article

\title{
Transcriptomic changes following the compatible interaction Vitis vinifera-Erysiphe necator. Paving the way towards an enantioselective role in plant defence modulation
}

\author{
Alexandre Filipe Borges ${ }^{a, b}, *$, Ricardo Boavida Ferreira ${ }^{a, b}$, Sara Monteiro ${ }^{b}$ \\ a Instituto de Tecnologia Química e Biológica, New University of Lisbon, Avenida da República, 2780-157 Oeiras, Portugal \\ ${ }^{\mathrm{b}}$ Instituto Superior de Agronomia, Technical University of Lisbon, Tapada da Ajuda, 1349-017 Lisboa, Portugal
}

\section{A R T I C L E I N F O}

\section{Article history:}

Received 15 January 2013

Accepted 26 March 2013

Available online 11 April 2013

\section{Keywords:}

Vitis vinifera

Erysiphe necator

Dirigent proteins

Secondary metabolism

\begin{abstract}
A B S T R A C T
The compatible interaction between Erysiphe necator and Vitis vinifera induces significant alterations in the host transcriptome, affecting essentially those genes involved in signalling and secondary metabolite biosynthetic pathways. The precise transcriptomic changes vary from the early events to later stages of infection. In the present work, suppressive subtraction hybridization (SSH) was used to identify several differentially expressed transcripts in symptomatic and asymptomatic leaves from powdery mildew infected grapevines following a long term interaction. The detected transcripts show little or no correlation with similar expression studies concerning the early stages of infection which suggests distinct host responses occur before and after the infection is established. The transcription level of thirteen genes was assessed through qRT-PCR using appropriately selected and validated normalization genes. With one exception, all these genes underwent moderate levels of differential transcription, with $\log _{2^{-}}$ fold change values ranging from -2.65 to 4.36 . The exception, a dirigent-like (DIR) protein, was upregulated over 180 fold in symptomatic leaves, suggesting an important role for stereochemical selectivity in the compatible interaction E. necator-V. vinifera. DIR copy number was determined in the genome of three grapevine cultivars exhibiting high (Carignan), moderate (Fernão Pires) and low (Touriga Nacional) sensitivity to E. necator. It was found to be a two-copy gene in all cultivars analyzed. Further analysis involving DIR metabolic neighbourhood transcripts was performed. The possible physiological significance of the detected DIR upregulation is discussed.
\end{abstract}

(c) 2013 Elsevier Masson SAS. All rights reserved.

\section{Introduction}

Erysiphe necator, the causal agent of powdery mildew (PM) in Vitis vinifera, represents, from an economic point of view, one of the most devastating diseases affecting grapevine worldwide [1]. Although its propagation can be minimized by chemicallysynthesized antifungal compounds, the inevitable increase in fungicides used to prevent and contain this disease comprises a potential environmental threat [2]. It is, therefore, of utmost importance to improve our knowledge on the molecular and biochemical mechanisms underlying $V$. vinifera-E. necator interaction. Numerous studies regarding this and other host-pathogen systems have shown that complex transcriptomic and subsequent

\footnotetext{
* Corresponding author. Instituto de Tecnologia Química e Biológica, Universidade Nova de Lisboa, Avenida da República, 2780-157 Oeiras, Portugal. Tel.: +351 213653194.

E-mail addresses: afgborges@isa.utl.pt, afgborges@gmail.com (A.F. Borges).
}

metabolic changes occur within the host in response to the pathogen [3]. As soon as the plant detects the presence of a pathogen, the induced defence response is triggered. Cell surfacelocated receptors are responsible for initial pathogen recognition, detecting pathogen-associated molecular patterns (PAMPs) and activating a kinase cascade-mediated signal transduction [4]. The resulting modifications range from upregulation of constitutive defence-related genes to transcriptionally induced or posttranscriptionally regulated disease-associated proteins, which may lead to PAMP-triggered immunity (PTI) [5]. Even though PTI can, occasionally, protect the plant from microbial invasion and/or proliferation during compatible interactions, it constitutes a nonhost-resistance mechanism against nonadapted pathogens [6].

When dealing with compatible plant-pathogen interactions, PTI is often, at least partially disabled through the use of effector proteins [5,7]. This is particularly relevant in pathosystems where the pathogen is an obligate biotrophic fungus, as in $V$. vinifera-E. necator interaction. Unlike facultative biotrophic or hemibiotrophic fungi which can survive outside the host or switch to necrotrophy, 
E. necator and other obligate biotrophic pathogens are entirely dependent on living plant tissue for their growth and propagation [8]. Therefore, they develop a highly sophisticated interaction with their hosts. Apparently, these pathogens have the ability to suppress or durably avoid pre-formed and induced host defences including hypersensitive response. In addition, they seem to be able to redirect the host metabolism according to their nutritional needs $[9,10]$.

Among all Vitis species, $V$. vinifera cultivars display the highest susceptibility to powdery mildew. Other species such as Vitis labrusca, Vitis rupestris and Vitis aestivalis exhibit several degrees of powdery-mildew resistance which can be somehow related to their co-evolution with E. necator during a long course of time [11]. A comparative transcriptomic study between $V$. vinifera and $V$. aestivalis suggests that the differential disease susceptibility among Vitis species goes beyond genome variation and is more likely to be determined by transcriptional regulation [12]. Recent evidence supporting this hypothesis shows a significant transcriptomic difference between compatible and incompatible interactions involving grapevine and E. necator. The differential gene expression induced by E. necator was observed to be limited to three transcripts in $V$. aestivalis against 625 PM-responsive genes found in $V$. vinifera up to $48 \mathrm{~h}$ postinoculation (hpi). The reason why such a weak PM-induced response occurs in $V$. aestivalis may be connected to its constitutive transcriptomic profile which is already defence-oriented when compared to $V$. vinifera [13]. The observed transcriptome changes in $V$. vinifera during the course of infection is consistent with the theory that these sophisticated pathogens are, somehow, able to circumvent host defence/recognition mechanisms [9]. Many differentially expressed defence-related proteins reached their maximum levels at $12 \mathrm{hpi}$ and then declined as the fungal infection became established [13]. Similar results were reported for barley (Hordeum vulgare) powdery mildew, where compatible and incompatible interactions with the pathogen Blumeria graminis caused analogous plant expression patterns during the first $16 \mathrm{~h}$ of infection. After this period, the expression of some of these defence-related genes declined to lower levels in susceptible plants, at 24 and 32 hpi [14]. Many of these genes are involved in plant secondary metabolism which, in $V$. vinifera-E. necator interaction, apparently shift the metabolism towards phenylpropanoid synthesis via the pentose phosphate and shikimate pathways. As a result, lignin, stilbene and dihydroflavonol metabolic branches are also upregulated.

Among all the differentially expressed reported genes, dirigent proteins (DIR) represent a particularly interesting defence-related multigene family [13]. DIR proteins (from Latin: dirigere = to guide or align) are proteins devoid of catalytic activity which dictate the stereochemistry of reactions catalyzed by other proteins. They were first reported as auxiliary proteins in lignan biosynthesis where they were shown to regio-stereochemically control the monolignol radical coupling catalyzed by peroxidases, namely dimerization of coniferyl alcohol to afford (+)-pinoresinol [15]. DIR discovery and their subsequent detection in all land plants examined to date explain the usually observed lignan optical activity in biological samples [16]. Lignans are characterized for their recognized antifungal activity, but also their chemical structure, with several chiral centres, allowing regio-stereochemical diversity along their biosynthetic route [17]. The observation that, under pathological conditions, this diversity is restricted to favour the formation of a single enantiomer highlights the potential importance of DIR enantioselective character in plant defence. Previous studies on lignan properties have already shown differential antimicrobial activity between enantiomers, one being up to four times more toxic than the other [18]. So far, a reasonable number of DIR/ DIR-like genes have been identified and phylogenetically grouped into six distinct subfamilies. Yet, little is known about the type or number of reactions they might assist. Until recently, DIR biochemical/physiological functions had only been assigned to members of the DIR-a subfamily, involving the guidance of coniferyl alcohol dimerization to afford (+)-pinoresinol [19]. Lately, members of DIR-b/d subfamily in cotton were also characterized as participating in terpenoid synthesis, namely in the enantioselective dimerization of hemigossypol to form (+)-gossypol [20]. There is also some evidence that DIR might be related with lignin biosynthesis, though this still remains a controversial issue [21]. Apart from those, and given the several thousand known plant lignans, DIR may participate in lignan formation other than (+)-pinoresinol.

In this study, we report the detection of several $V$. vinifera defence-related genes whose expression was found to be affected following the long term interaction with E. necator. The comparison between our results and similar studies performed during this plant-pathogen interaction indicates that distinct host modifications occur during the initial and late stages of infection. The differential gene expression between symptomatic and asymptomatic leaves of powdery mildew infected grapevines was confirmed and quantified by qRT-PCR using previously validated normalization genes. Among the detected transcripts a DIR-like gene was identified whose differential expression highlights its potential importance in this plant-pathogen interaction. We further investigated whether $V$. vinifera DIR gene dosage could be related to $E$. necator susceptibility, determining genomic DIR copy number for grapevine cultivars with different PM susceptibility degrees. DIR was found as a two-copy gene in all three cultivars analyzed. Moreover, an attempt was made to correlate the observed DIR upregulation with the relative transcript levels of several genes participating in the metabolic surroundings of coniferyl alcohol, the putative DIR "substrate". Our data suggest that either an alternative lignan biosynthetic pathway exists or DIR may be involved in reactions other than the dimerization of coniferyl alcohol.

\section{Results}

\subsection{SSH cDNA libraries}

To identify differentially expressed genes between symptomatic (S) and asymptomatic leaves (A) from powdery-mildew infected grapevines, two cDNA libraries were constructed from forward and reverse suppressive subtraction hybridization (SSH) using $\mathrm{S}$ and $\mathrm{A}$ samples as testers, respectively. A total of 273 clones from both forward and reverse subtractions were screened for relative transcript abundance in the subtracted cDNA pools. Significant dot-blot hybridization differences were observed for 62 clones for which the corresponding cDNA inserts were sequenced. Sequence analysis revealed 28 non-redundant grapevine transcripts (Table 1) and three E. necator transcripts. Most inserts ranged from 300 to $800 \mathrm{bps}$. Highquality cDNA sequences obtained for 24 transcripts were deposited and made accessible in the dbEST NCBI database. tBLASTx analysis allowed us to assign a predicted function to 19 transcripts due to their very high similarity with known function genes from other plant species. Three of the selected transcripts revealed homologies with grapevine predicted proteins of unknown function. Six sequences showed no significant similarity to known or putative function genes but were homologues to grapevine genomic sequences. The presence of $\operatorname{poly}(A)$ tails in the latter confirms they represent grapevine transcripts and thus, new uncharacterized genes.

\subsection{Validating internal controls for $q R T-P C R$}

To perform the qRT-PCR gene expression studies between $\mathrm{S}$ and $\mathrm{A}$ leaf samples, the identification of the most suitable housekeeping genes to be used as internal controls was a first priority. The 
Table 1

Differentially expressed transcripts detected by SSH of symptomatic (S) and asymptomatic leaves (A) from powdery-mildew infected grapevines.

\begin{tabular}{|c|c|c|c|c|}
\hline Clone ID (accession number) & Subtraction library ${ }^{a}$ & Predicted function & tBLASTx & $E$ value \\
\hline F1B5 (KC748395) & Forward & Glycerol-3-phosphate dehydrogenase-like & XM_002284443 & $9 \mathrm{E}-141$ \\
\hline F1C5 (KC748400) & Forward & Beta-amyrin synthase/triterpene synthase & XM_002269309 & $1 \mathrm{E}-24$ \\
\hline F1A11 (KC748406) & Forward & Resveratrol- $O$-methyltransferase & XM_002281445 & $8 \mathrm{E}-39$ \\
\hline F1D5 (KC748408) & Forward & Mitogen-activated protein kinase & XM_003633911 & $1 \mathrm{E}-149$ \\
\hline F1E6 (KC748418) & Forward & Dirigent-like protein & XM_002276412 & $2 \mathrm{E}-80$ \\
\hline F1A12 (KC748407) & Forward & Calcium-binding EF hand family protein & AM476824 & $2 \mathrm{E}-142$ \\
\hline F2C4 (KC748411) & Forward & Tyrosine kinase & XM_003635112 & $2 \mathrm{E}-70$ \\
\hline F2C6 (KC748412) & Forward & Wall-associated kinase & XM_003631669 & $4 \mathrm{E}-82$ \\
\hline F1C7 (KC748413) & Forward & Potassium transporter & XM_002264915 & $1 \mathrm{E}-75$ \\
\hline F1A3 (KC748403) & Forward & Ribosomal protein s15a & XM_003632560 & $4 \mathrm{E}-95$ \\
\hline F1D11 (KC748415) & Forward & Vitis vinifera - unknown/uncharacterized & XM_002277671 & $4 \mathrm{E}-94$ \\
\hline $\mathrm{F} 2 \mathrm{~A} 4$ & Forward & Vitis vinifera - unknown/uncharacterized & XM_003632258 & $6 \mathrm{E}-98$ \\
\hline F2A5 (KC748404) & Forward & Vitis vinifera - unknown/uncharacterized & XM_003631832 & $8 \mathrm{E}-112$ \\
\hline F1A2 & Forward & Vitis vinifera contig VV78X174488.4 & AM441276 & $1 \mathrm{E}-87$ \\
\hline F1C2 (KC748409) & Forward & Vitis vinifera contig VV78X257382.43 & AM476899 & $6 E-136$ \\
\hline F1C11 & Forward & Vitis vinifera contig VV78X054516.4 & AM482143 & $3 E-36$ \\
\hline F2D1 (KC748414) & Forward & Vitis vinifera contig VV78X057541.5 & AM441985 & $2 \mathrm{E}-102$ \\
\hline F1E5 (KC748417) & Forward & Vitis vinifera contig VV78X104455.3 & AM484817 & $6 \mathrm{E}-112$ \\
\hline R1D10 (KC748416) & Reverse & Oligopeptide transporter protein & XM_002274130 & $7 \mathrm{E}-130$ \\
\hline R2C3 (KC748410) & Reverse & Hormone-sensitive lipase/gibberellic acid receptor & XM_002265728 & $8 \mathrm{E}-59$ \\
\hline R1C7 (KC748397) & Reverse & Cinnamoyl-CoA reductase, putative & XM_002272413 & $1 \mathrm{E}-138$ \\
\hline R1D7 (KC748401) & Reverse & Zinc-finger RING-type protein-like & XM_002285229 & $1 \mathrm{E}-154$ \\
\hline R1C11 (KC748402) & Reverse & Oligouridylate binding protein & XM_002276972 & $3 E-151$ \\
\hline R2A10 (KC748405) & Reverse & Carbohydrate transporter & XM_002278696 & $1 \mathrm{E}-62$ \\
\hline R1A8 (KC748398) & Reverse & GPI-anchored protein & XM_002272370 & $8 \mathrm{E}-119$ \\
\hline $\mathrm{R} 1 \mathrm{C} 2$ & Reverse & MYB/MYC transcription factor & XM_002282950 & $9 \mathrm{E}-120$ \\
\hline R1B11 (KC748399) & Reverse & ATPase alpha subunit & GQ220323 & $9 \mathrm{E}-155$ \\
\hline R1C1 (KC748396) & Reverse & Vitis vinifera contig VV78X123770.2 & AM425900 & $4 \mathrm{E}-126$ \\
\hline
\end{tabular}

${ }^{a}$ Forward and reverse SSH were performed using S and A samples as testers, respectively.

candidate genes were evaluated according to their expression stability under the particular experimental conditions tested in the present study. Six commonly used housekeeping genes [22-24] were selected and their relative transcript abundance in $S$ and $A$ cDNA samples was subsequently evaluated using geNorm software [25]. The expression stability for ribosomal protein L2 (L2), elongation factor 1 alpha (EF1alpha), cyclophilin (Cyp), phosphoenolpyruvate carboxylase (PEPcase), ubiquitin conjugating enzyme (UBC) and vacuolar ATP synthase subunit G (VAG1) was tested. For each candidate gene, a gene-stability parameter $(M)$ was determined (Fig. 1A) which reflects its expression variation between samples by pairwise comparison with all genes under analysis. Genes with the lowest $M$ values are the most stably expressed. This analysis revealed $U B C$ and VAG1 as the best ranked housekeeping control genes for this study, immediately followed by PEPcase (Fig. 1A).
To determine the optimal number of internal control genes required for reliable normalization, geNorm was used to calculate the pairwise variation $\left(V_{n / n+1}\right)$ between two sequential normalization factors $\left(\mathrm{NF}_{n}\right.$ and $\left.\mathrm{NF}_{n+1}\right)$ (Fig. $\left.1 \mathrm{~B}\right) . V_{n / n+1}$ reflects the accuracy changes accompanying the inclusion of an $(n+1)$ th gene as internal control. The lower the $V$ value, the more stable is the corresponding normalization factor. A cut-off threshold was set at $V=0.15$ below which the additional control gene has no significant effect in data normalization [25]. As shown in Fig. 1B, under our experimental conditions, $V_{2 / 3}$ was 0.13 , which was below the cut-off threshold. Thus, the addition of a third control gene has negligible effects on the normalization factor and, therefore, the use of the two most stable genes as internal controls, i.e. $U B C$ and $V A G 1$, is enough for reliable data normalization.

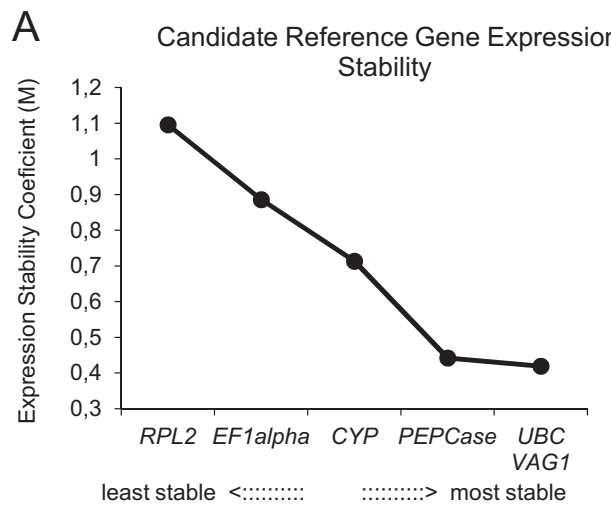

B Optimal Number of Reference Genes

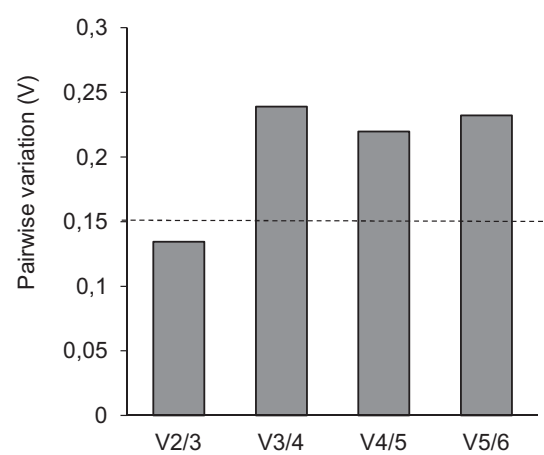

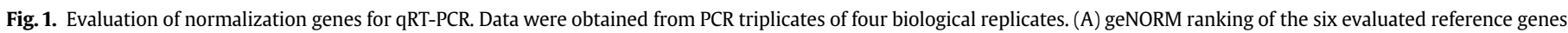

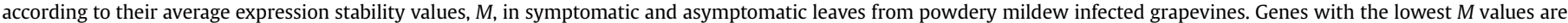

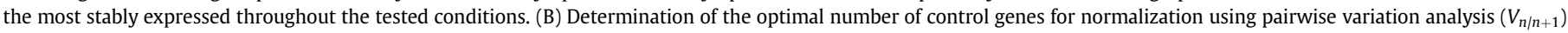
between the normalization factors $\mathrm{NF}_{n}$ and $\mathrm{NF}_{n+1}$. A cut-off threshold of 0.15 indicates that the addition of a third control gene has no significant effect in data normalization. 


\subsection{Differential gene expression quantification by real-time RT-PCR}

To confirm and quantify the differential gene expression levels detected by $\mathrm{SSH}$, relative transcript quantification between $\mathrm{S}$ and $\mathrm{A}$ samples was performed using qRT-PCR. PCR primers were designed for all 19 transcripts (Table 2) for which a predicted function could be established. Amplification specificity for each primer pair was evaluated by both BLASTn and melting curve analysis. Yet, eight genes were excluded from the study either due to unspecific amplifications or primer-dimer formation. In addition to the selected genes, the relative expression levels of actin and ribosomal protein L2, two widely used internal controls, were also measured to

Table 2

qRT-PCR primers.

\begin{tabular}{|c|c|c|c|}
\hline Primer & & Sequence $5^{\prime}$ to $3^{\prime}$ & $E^{\mathrm{a}}$ \\
\hline \multirow[t]{2}{*}{ Triterpene synthase } & FW & TCACTCCATCAACCTCAGAAG & nd \\
\hline & RV & CCCAGAAGAGCGAGAAGAG & \\
\hline \multirow{2}{*}{$\begin{array}{l}\text { Resveratrol-vO } \\
\text {-methyltransferase }\end{array}$} & FW & TGAGGTTCAAGGTTGGAATATG & nd \\
\hline & RV & TGGTTGTGGATGATGTCTGG & \\
\hline \multirow[t]{2}{*}{ DIR } & FW & CCAGCACTCATACAACTTAATATCAAC & nd \\
\hline & RV & CTCAACAGCACAGACTTTCAGG & \\
\hline \multirow{2}{*}{$\begin{array}{l}\text { Glycerol-3-phosphate } \\
\text { dehydrogenase }\end{array}$} & FW & GCAACACGCTCAAG & nd \\
\hline & RV & TGGCTGACACCTATG & \\
\hline \multirow[t]{2}{*}{ MAPK } & FW & CAACTATGACACAAAGGAAGAAG & nd \\
\hline & RV & CATTTACTGAAGAGAATATCAAAGAAC & \\
\hline \multirow[t]{2}{*}{ Oligopeptide transporter } & FW & TATTGGAATAATCTACAGCGTGATAGTG & nd \\
\hline & RV & GAAGACGAAGGCGAGCAGAG & \\
\hline \multirow[t]{2}{*}{ Gibberellic acid receptor } & FW & AGTAGAAGCCGATTGTTGC & nd \\
\hline & RV & AGAGTCTTGTTGTGGTTGC & \\
\hline \multirow[t]{2}{*}{ Inositol transporter } & FW & GTAATAAGGTATCCAGTTGTTCAATG & nd \\
\hline & RV & СТTССТСТСАAАTTCAGTCTATCG & \\
\hline \multirow[t]{2}{*}{ Cinnamoyl-CoA reductase } & FW & GGTTGGAGATGGTGAGATG & nd \\
\hline & RV & CTTGACGAGAGAAACTGGAG & \\
\hline \multirow{4}{*}{$\begin{array}{l}\text { Oligouridylate } \\
\text { binding protein } \\
\text { Zinc-finger RING-type } \\
\text { protein }\end{array}$} & FW & AAGGTGCTGGAGGTAACG & nd \\
\hline & RV & ATGTCGGTGGAGGTCAAC & \\
\hline & FW & TGAGATAGCCAGACAAGTAG & nd \\
\hline & RV & TTGCCTCCACCATTGC & \\
\hline \multirow[t]{2}{*}{ Actin (XM_002282480.2) } & FW & TGGATTCTGGTGATGGTGTGAGTC & nd \\
\hline & RV & CAATTTCCCGTTCAGCAGTAGTGG & \\
\hline \multirow[t]{2}{*}{ L2 (AJ441290.2) } & FW & TCTACTTCAACCGATATGC & 0.89 \\
\hline & RV & CCACCTGTCCGACTG & \\
\hline \multirow[t]{2}{*}{ PEPCase (AF236126.1) } & FW & ССТССТССТССАGATTGC & 0.86 \\
\hline & RV & GGCTTGCTTGATTCCATTATC & \\
\hline \multirow[t]{2}{*}{ UBC (EE253706) } & FW & CATAAGGGCTATCAGGAGGAC & 0.95 \\
\hline & RV & TGGCGGTCGGAGTTAGG & \\
\hline \multirow[t]{2}{*}{ Cyp (ES880796) } & FW & ACAGCCAAGACCTCGTG & 0.90 \\
\hline & RV & GCCTTCACTGACCACAAC & \\
\hline \multirow[t]{2}{*}{ VAG1 (XM_002281110.1) } & FW & TTGCCTGTGTCTCTTGTTC & 1.11 \\
\hline & RV & TCAATGCTGCCAGAAGTG & \\
\hline \multirow[t]{2}{*}{$E F 1 \alpha(G U 585871.1)$} & FW & GAACTGGGTGCTTGATAGGC & 0.87 \\
\hline & RV & AACCAAAATATCCGGAGTAAAAGA & \\
\hline \multirow[t]{2}{*}{ UFGT (JF522535.1) } & FW & GGTGGTTTTACCTGCTAATTTGTT & nd \\
\hline & RV & GTGAGAAGAGCGAGTTTAGGTTTC & \\
\hline \multirow[t]{2}{*}{ DFR (AY780886.1) } & FW & TCATCACTATCATACCGACTCTTGT & nd \\
\hline & RV & CCTGCCGTATAATTGAATGAGC & \\
\hline \multirow[t]{2}{*}{ AR (XM_002282806.1) } & FW & TCTATCAGCACCATCACAGCCAAGG & nd \\
\hline & RV & ССААССАСССАСТСТСGТСТTСC & \\
\hline ConGlu (XM_002264642.2) & FW & TCTCTTGGAGTCAACAGCTACCG & nd \\
\hline & RV & TCAСТTСТССАААТСТСССТTCGG & \\
\hline$P R R^{\mathrm{b}}$ & FW & TTCTTGTDGTGGGTGGVACAGGSTA & nd \\
\hline & RV & ACCAYATYTACTTTCTTCACWGCTT & \\
\hline $\mathrm{CaOMT}^{\mathrm{b}}$ & FW & TCSMCCRGTATGAYCCCARMAACTA & nd \\
\hline & RV & TGGKGAYCTKAGCAGCAATCT & \\
\hline$C A D^{\mathrm{b}}$ & FW & AAATGSGTAGCCTTGRGACTGA & nd \\
\hline & $\mathrm{RV}$ & TCYGATCCCACCTCCACC & \\
\hline UDP-GT (XM_002273320.1) & FW & АСТССТСАТСТСССТААСТTGСТG & nd \\
\hline & RV & TTCATGGCCGAGATTGCAGAG & \\
\hline F5H (XM_002272608.2) & FW & TCCGACTCCACCСАCСТАТT & nd \\
\hline & $\mathrm{RV}$ & GCCCGCTTTGAGAAACCTTG & \\
\hline
\end{tabular}

nd - Not determined.

a Primer pair amplification efficiency.

b Degenerate primer. evaluate their adequacy as normalization factors in qRT-PCR studies on this host-pathogen interaction. The relative gene expression levels between $S$ and A mRNA samples is represented in Fig. 2.

With the exception of KC748416, representing an oligopeptide transporter, all SSH-detected transcripts were found to be present in significantly different amounts in symptomatic and asymptomatic samples. The agreement observed in all cases between the cDNA library, from where the transcripts were identified (forward or reverse $\mathrm{SSH}$ ), and their correspondent up or downregulation also validates the subtraction process (Table 1, Fig. 2). Overall, the analyzed genes present slightly moderate levels of differential expression with $\log _{2}$ (fold change) values ranging from -2.65 to 4.36 for L2 ribosomal protein and glycerol-3-phosphate dehydrogenase, respectively. Among all the transcripts, the dirigent-like protein (DIR) (KC748418) stands out of the remaining due to the magnitude of overexpression in symptomatic leaves when compared to asymptomatic ones. Its upregulation reaches over 180 fold change, representing a variation 10-150 times larger than that observed for the remaining transcripts.

\subsection{Genomic DIR copy number determination in $V$. vinifera cultivars}

To assess whether DIR gene dosage could be somehow relevant in $V$. vinifera-E. necator interaction, qPCR was used to determine the DIR copy number in three $V$. vinifera cultivars with different powdery mildew susceptibilities. Genomic DNA from the cultivars Carignan, Fernão Pires and Touriga Nacional was used as template for $V$. vinifera cultivars with high, moderate and low powdery mildew susceptibility, respectively. The powdery mildew susceptibility degree of each cultivar was assessed according to the empirical ranking provided by Dr. Antero Martins and co-workers (ISA/PORVID), which is based on their wide viticulture experience and field observations.

Given the individual DNA quality patterns obtained from the three $V$. vinifera cultivars, accurate spectrophotometric DNA quantification was not feasible and thus absolute quantification of DIR gene copy number was not carried out. Instead, a relative quantification procedure was selected using cultivar Pinot Noir genomic DNA as calibrator and three single-copy genes as reference. According to the grapevine genome sequence available at Genoscope (http://www.genoscope.cns.fr/spip/), DIR is a two-copy gene in Pinot Noir, while UDP-glucose:flavonoid 3-O-glucosyltransferase (UFGT), dihydroflavonol reductase (DFR) and anthocyanidin reductase $(A R)$ are products of single-copy genes. DIR copy number was calculated (Fig. 3 ) based on the $E^{-\Delta C t}$ ratios between DIR and single-copy genes according to the following equation:

DIR copy number $=\frac{E_{D I R}^{\Delta \mathrm{Ct}(\text { calibrator-cultivar })}}{E_{\text {ref }}^{\Delta \mathrm{Ct}(\text { calibrator-cultivar })}} \times 2$

where $E=$ amplification efficiency of the gene (DIR or reference) and $\Delta \mathrm{Ct}=$ calibrator $\mathrm{Ct}-$ cultivar $\mathrm{Ct}$ from the respective gene.

No significant differences in the determined $E^{-\Delta C t}$ ratios were observed for each of the three cultivars (Fig. 3), indicating that DIR is a two-copy gene in the genomes of the cultivars Carignan, Fernão Pires and Touriga Nacional. Therefore, the different degree of susceptibility exhibited by $V$. vinifera cultivars to E. necator infection does not seem to be related to DIR copy number.

\subsection{Coniferyl alcohol branching genes}

Up to date, almost all the described DIR-assisted reactions involve coniferyl alcohol dimerization to afford (+)-pinoresinol 


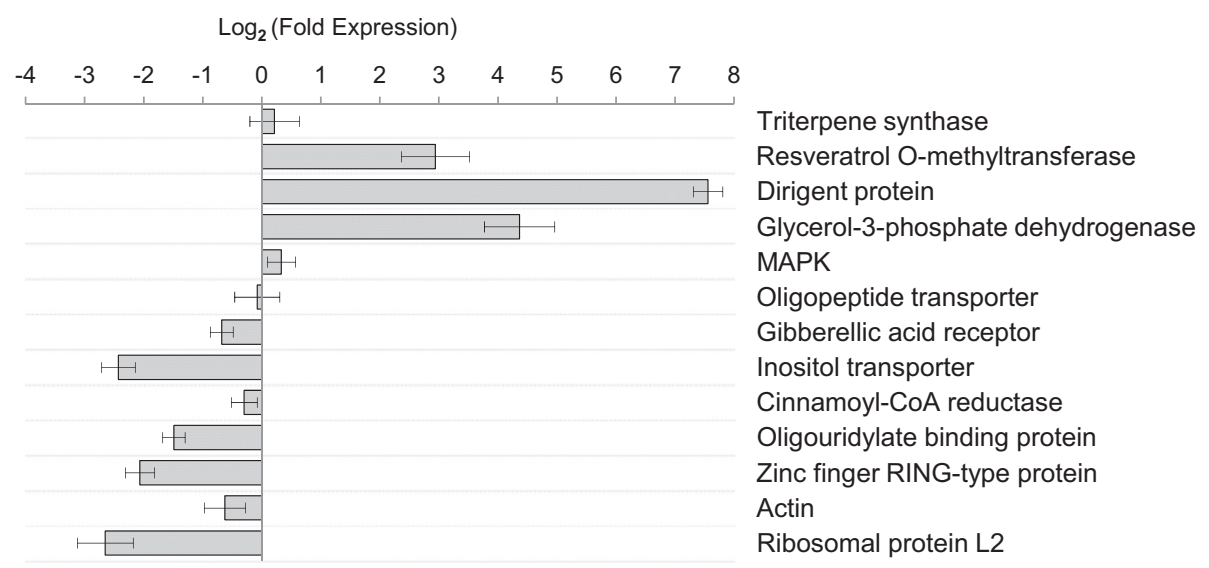

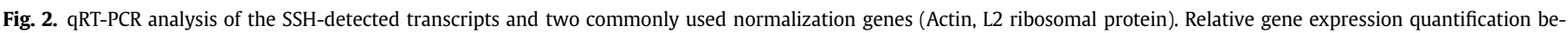

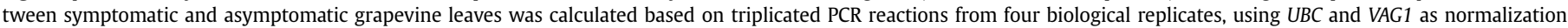
genes.

[26]. Given the substantial DIR upregulation in E. necator-infected symptomatic grapevine leaves, a transcriptomic approach was applied to analyze the "metabolic neighbourhood" directly concerned with, or centred in coniferyl alcohol (Fig. 4). The metabolic pathway information was obtained through KEGG database [27,28]. The main objective was to investigate whether the differential transcription observed for SSH-identified DIR was consistent with the ones from the remaining branching genes, regarding the reported coniferyl alcohol metabolic fate (i.e. yield of $(+)$-pinoresinol). According to the phenylpropanoid metabolic pathway described for several plant species, which is illustrated in Fig. 4, a study on the relative expression of the genes encoding caffeic acid $O$-methyltransferase (CaOMT), coniferyl-alcohol dehydrogenase $(C A D)$, ferulate-5-hydroxylase $(F 5 H)$, coniferyl-alcohol glucosyltransferase (UDP-GT), coniferin beta-glucosidase (ConGlu) and pinoresinol reductase ( $P R R$ ) was conducted. The $V$. vinifera genome database was searched for each of the previous gene orthologues and PCR primers were designed (Table 2) within the conserved regions of each orthologue family. Melting curve analysis for both UDP-GT and ConGlu amplicons consistently revealed non-specific amplifications, a result which did not allow data gathering concerning the interconversion between coniferyl-alcohol and coniferin. Relative transcription $\log _{2}$ (fold values) determined for the remaining coniferyl-alcohol branching genes is shown in Fig. 5.

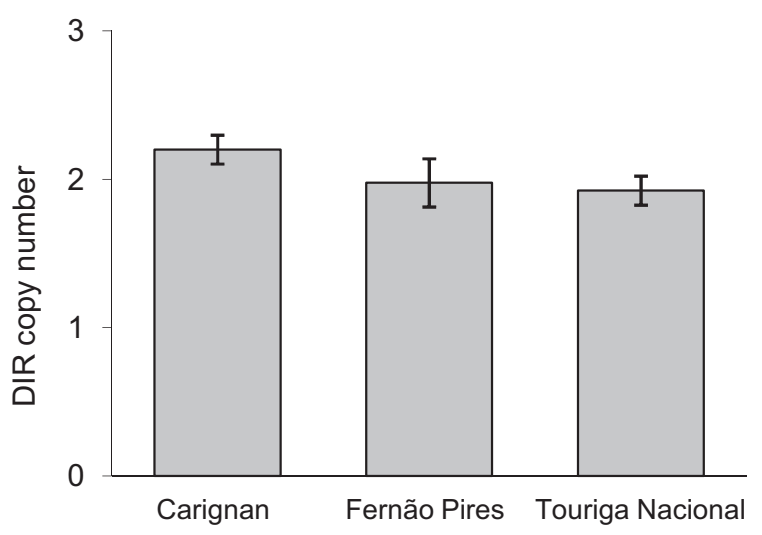

Fig. 3. Genomic DIR copy number from grapevine cultivars with different powdery mildew susceptibilities. Absolute copy number was determined through qPCR using the relative quantification method where the genomic DNA of Pinot Noir was used as calibrator. Three Pinot Noir single-copy genes were used for normalization.

\section{Discussion}

\subsection{SSH cDNA libraries}

In contrast to conventional transcriptomic studies, regarding plant-pathogen interactions, where the experimental design is set to identify early or midterm host responses induced by the pathogen, the experimental approach followed in the present work emphasizes long term transcriptional modifications. Moreover, it focuses on differential expression patterns occurring within the host tissues ( $V$. vinifera leaves) due to prolonged and successful fungal colonization when compared to tissues that, although having been exposed to E. necator spores, remain asymptomatic. PAMPtriggered immunity (PTI) and systemic acquired resistance (SAR) constitute key elements in plant defence mechanisms [29]. However, PTI relies on the recognition of highly conserved epitopes among pathogens and thus, comprises, along with pre-formed chemical and physical barriers, a nonhost-resistance mechanism [30]. Conversely, SAR is based on much higher degree of specificity towards pathogens and is mediated by the products of disease resistance $(R)$ genes after the plant is locally infected by the pathogen [31]. Nevertheless, apart from the initial recognition process, both PTI and SAR seem to share downstream signalling machinery
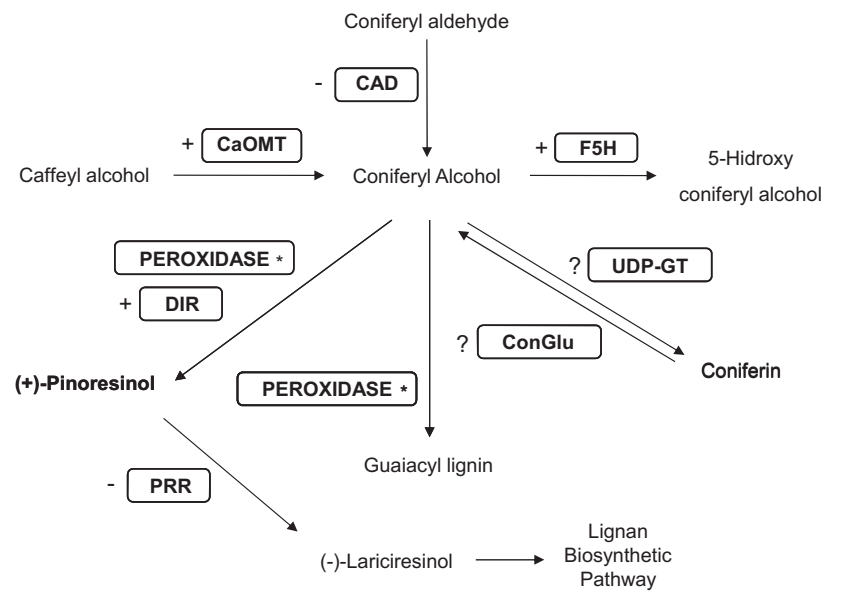

Fig. 4. Coniferyl alcohol branching enzymes. Overview of $V$. vinifera genes directly involved in coniferyl alcohol metabolism and their determined up $(+)$ /downregulation(-) in E. necator symptomatic leaves. 


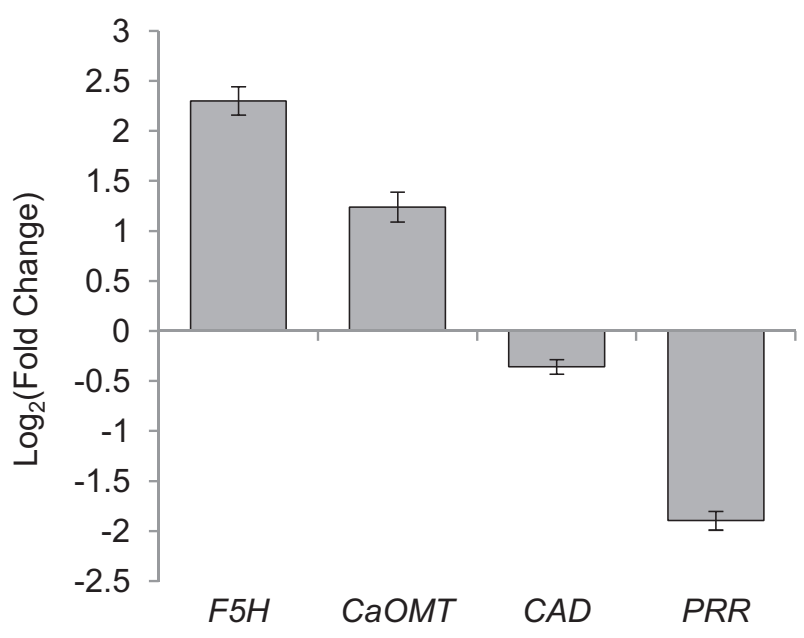

Fig. 5. qRT-PCR analysis of the coniferyl alcohol related genes. Relative gene expression quantification between symptomatic and asymptomatic grapevine leaves was calculated based on triplicated PCR reactions from two biological replicates, using $U B C$ and VAG1 as normalization genes.

and essentially differ from one another by the extent of the pathogen-induced responses, transient in PTI and prolonged in SAR [32].

By applying the SSH technique to determine differentially expressed genes between symptomatic (S) and asymptomatic (A) leaves from powdery mildew infected grapevine (V. vinifera, cv. Touriga Nacional), the genes exclusively involved in PTI are expected to be overlooked. Given that, in this study, S and A samples were both collected from plants exposed to the same initial external stimulus and subsequently grown for 30 days with generalized powdery mildew infection, it is reasonable to assume that at least some of the detected transcript changes will be a consequence of an activated SAR mechanism. Moreover, the detection of mRNA variations reflecting host attempts to maintain homoeostasis is expected while excessive nutrient consumption is occurring due to the pathogen presence. In addition, the pathogen also exerts pressure to modulate the host gene expression to its own benefice. In other words, this experimental approach accounts for the permanent host genetic manipulation by the pathogen to fulfil its nutritional needs and to suppress the host specific recognition mechanisms. Anyhow, without additional data, the SSHdetected transcripts (Table 1) can only be assigned to standard functional classes: signalling processes and secondary metabolite biosynthetic pathways, which for the most part concern genes associated with defence-related mechanisms.

The apparently reduced number of SSH-identified genes may be tentatively explained by the premise that the cDNA library screening process, namely the use of non-radioactive labelled probes, did not show enough sensitivity to discriminate between the individual relative transcript abundance of both cDNA subtraction pools. Thus, despite the positive evidence on the subtraction efficiency, an unknown number of the overall "subtracted" transcripts may not have been detected in this study.

\subsection{Validation of reference genes for $q R T-P C R$ studies}

qRT-PCR is currently one of the most powerful and sensitive techniques for the rapid and reliable quantification of gene transcript levels. Yet its accuracy relies heavily on appropriate normalization procedures to compensate for sample differences such as initial amount, RNA integrity, enzymatic efficiencies, and differences in the overall transcriptional activity of the tissues under analysis [33]. In recent years it became clear that the traditional housekeeping genes used for normalization in northern blots or semi-quantitative RT-PCR were not suitable enough when higher sensitivity techniques are used [34]. Nevertheless, to date, many gene expression studies have been published without an appropriate reference gene selection. In the present study, the need to accurately validate the internal controls used in qRT-PCR for each experimental condition tested was further emphasized. A set of six commonly used reference genes was tested for expression stability under the experimental conditions analyzed in this study using the geNorm algorithm. The candidate reference gene selection criteria must account for potential co-regulation between candidates, since their stability assessment relies on the principle that the expression ratio between two ideal reference genes is identical in all samples. Therefore, identically regulated genes tend to be top ranked in geNorm even if their expression levels fluctuate considerably among samples [25]. Accordingly, and to address this issue, the reference gene candidates were chosen on the basis of their participation in distinct cellular metabolic pathways: ribosomal protein L2 [34], elongation factor 1 alpha [33], cyclophilin [23], phosphoenolpyruvate carboxylase [35], ubiquitin conjugating enzyme [36] and vacuolar ATP synthase subunit G [24].

Reasonably, given the nature of the host-pathogen interaction under study, the evaluation of other commonly used housekeeping genes, such as glyceraldehyde-3-phosphate dehydrogenase, actin or tubulin, was not considered. Biotrophic pathogens, like E. necator, are known for their essential and highly specialized infection structures, the haustoria [9]. Among other functions, haustoria are responsible for the nutrient supply of the pathogen, uptaking amino acids and monosaccharides from the host cells [37]. Hence, the pathogen is expected to directly and greatly affect carbohydrate pools in the host, making genes encoding glycolytic enzymes such as glyceraldehyde-3-phosphate dehydrogenase highly likely targets for gene transcriptional modulation and therefore unsuitable to be used as reference genes in qRT-PCR. For similar reasons, actin and tubulin were not within the group selected for candidate reference genes. Plant cytoskeleton is well known to play an important role in defence against pathogens, with several studies reporting actin and tubulin rearrangements in the host upon pathogen attack [38].

To become aware of the possible bias magnitude generated by the use of an inadequate reference gene selection, the relative transcription levels of the genes encoding actin and the ribosomal protein L2 were measured. The poor stability of the former had already been shown for biotic stress in potato [23], whereas the latter was shown to be the worst ranked candidate in the present study. Both actin and ribosomal protein L2 are downregulated in symptomatic leaves (when compared to asymptomatic ones), with approximate fold-change values of -1.5 and -6.3 , respectively (Fig. 2). These data confirm the study of Derveaux and colleagues, who reported that small changes in expression levels should not be based on single non-validated reference genes to prevent significantly biased results [39].

\subsection{Differential gene expression quantification by $q R T-P C R$}

Regarding the SSH-identified transcripts and independently of the relative expression quantification accuracy, one cannot get into profound considerations about their role in plant defence. Still it is possible to correlate our results with others described in the literature as far as plant pathogen interactions are concerned. It was interesting to notice that none of the detected genes had correspondence with the ones detected by Fekete et al. which performed a similar gene expression study during the early stages (up to $48 \mathrm{~h}$ ) 
of $E$. necator infection in grapevine leaves [40]. Such observation highlights the infection process dynamics evidencing distinct host transcriptional responses/modifications during the course of infection. Moreover, within the time lapse Feteke carried his experiments, significant differential expression changes were also observed along the first $48 \mathrm{~h}$ of infection. We therefore consider that the present study provides novel and valuable information about $V$. vinifera-E. necator interaction in the sense that it describes transcriptomic changes occurring long after the infection is established and possibly illustrates host manipulation by the pathogen and the systemic acquired resistance mechanism developed by the asymptomatic leaves of the plant.

As mentioned before, the majority of the detected genes in the present study belong to signalling pathways or to secondary metabolite biosynthetic routes. The most relevant genes are discussed.

F1B5 EST (KC748395), coding for a glycerol-3-phosphate dehydrogenase, was found to be upregulated in powdery mildew symptomatic leaves, with a fold-change value of +20.6 when compared to asymptomatic leaves. Glycerol-3-phosphate was recently reported as a regulator of plant defence signalling. Although the mechanisms underlying this signalling pathway remain unexplored, it has been shown that Arabidopsis thaliana mutants in glycerol-3-phosphate synthesizing genes, such as glycerol kinase or glycerol-3-phosphate dehydrogenase, display enhanced susceptibility to Colletotrichum higginsianum, a hemibiotrophic ascomycete responsible for anthracnose disease in Brassica sp. [41].

Clone R2A10 (KC748405), codes for an inositol transporter, which was observed to be downregulated ( -5.38 fold change) in symptomatic leaves. Myo-inositol plays an important role as the structural basis for a number of secondary messengers in the signal transduction pathways which modulate intracellular events through free $\mathrm{Ca}^{2+}$ level regulation [42]. Though ubiquitous in biochemical pathways, myo-inositol metabolism is regarded to intervene in elicitor-induced phytoalexin production and programmed cell death $[43,44]$. This makes sense as part of the overall fungal strategy in keeping the host defences low during the longtime it operates as a parasite of grapevine leaves.

R2C3 EST (KC748410), codes for a hormone-sensitive lipase (downregulated: -1.60 fold change) with high homology for a gibberellic acid receptor. Besides playing an important role in plant growth and development, gibberellic acid hormonal signalling is also involved in plant defence mechanisms. Moreover, it has been reported as a potential manipulation target in host-microbe compatible interactions [45].

Concerning clone F1D5 (KC748408), coding for a mitogenactivated protein kinase (MAPK), a slight powdery mildewinduced upregulation $(+1.26$ fold change) was observed. MAPK cascade-mediated signalling is an essential step in the establishment of resistance to pathogens [4]. Within the MAPK family, F1D5 displays the highest homology with MAPK4, which negatively regulates biotic stress signalling, namely systemic acquired resistance [46].

According to our results, R1C7 transcript (KC748397), highly similar to cinnamoyl-CoA reductase (CCR), was weakly repressed in symptomatic leaves. Being a key enzyme in lignin biosynthetic pathway, its regulation directly affects lignin deposition patterns in plants [47]. Several genes encoding CCR have already been shown to be associated to both developmental stages and biotic/abiotic stresses [47-49]. The lignification process can be an important step towards pathogen resistance, either through lignin deposition or formation of lignin-like compounds [50,51]. Thus, the observed CCR downregulation, in this case, can hypothetically be perceived as host manipulation by the pathogen.
An overexpression in symptomatic leaves regarding clone $\mathrm{F} 1 \mathrm{C} 5$ (triterpene synthase), F1A11 (resveratrol-O-methyltransferase) and F1E6 (DIR) was also observed. The corresponding genes are directly involved in the synthesis of secondary metabolites exhibiting antimicrobial properties. Triterpene synthases are oxidosqualene cyclases catalyzing the cyclization of 2,3oxidosqualene to afford triterpenoid compounds such as lupeol, betulinic acid or beta-amyrin [52,53]. The SSH-detected oxidosqualene cyclase (KC748400) has the highest homology with beta-amyrin synthase. trans-Resveratrol, a trihydroxystilbene phytoalexin is, per se, an antifungal compound reported to be produced in plants in response to pathogen attack [54]. Nevertheless, subsequent trans-resveratrol metabolic modifications, like dimerization or $O$-methylation, can yield products with enhanced antifungal activity [55]. O-Methylation of trans-resveratrol to afford pterostilbene, a highly toxic metabolite, is catalyzed by resveratrol-O-methyltransferase, whose expression was observed to increase in grapevine leaves upon downy mildew infection [56]. This correlates well with the present work where the SSH-detected resveratrol-O-methyltransferase (KC748406) is upregulated in grapevine leaves ( +7.68 fold change) due to $E$. necator colonization. Dirigent proteins, although devoid of enzymatic activity, play an important role as chiral auxiliaries to direct the stereochemistry of the reactions in which they participate $[15,20]$. Up to date, most of the functionally characterized dirigent proteins were shown to participate in lignan biosynthesis, namely in the dimerization of coniferyl alcohol to afford (+)-pinoresinol, a key step in lignan biosynthesis [16]. Lignans constitute an abundant class of phenylpropanoid dimers, well recognized for their antifungal properties $[57,58]$. Among the SSH-detected transcripts, the gene encoding the dirigent protein (KC748418) displayed by far the highest differential transcription level between symptomatic and asymptomatic leaves from powdery mildew infected grapevine. Its upregulation magnitude in symptomatic leaves reached fold-change values up to 150 times higher than the remaining SSH-detected transcripts, highlighting a great potential relevance in plant defence mechanisms.

\subsection{Dirigent proteins}

Genes encoding dirigent proteins have been described as being constitutively expressed at very low levels but rapidly induced in response to biotic stress $[19,59]$. This is consistent with the observed upregulation intensity for the detected dirigent protein gene. Considering the potentially important role of DIR in plant protection against pathogens and the low constitutive expression level of the gene encoding it, the transcriptional rate, and thus the speed at which the plant reacts to stress, could be limited by gene dosage. Therefore, since no data could be gathered about $E$. necatorinduced DIR transcription in grapevine cultivars with different powdery mildew susceptibilities, DIR gene copy number was determined for three $V$. vinifera cultivars (Carignan, Fernão Pires, and Touriga Nacional). All three cultivars were shown to possess an equal number of DIR copies in their genome, which was the same as that contained in Pinot Noir. Thus, it is possible to conclude that powdery-mildew susceptibility in $V$. vinifera cultivars is not directly correlated to DIR gene copy number, despite the apparent great potential importance played by DIR in plant protection against pathogens.

Considering the genes differentially transcribed between symptomatic and asymptomatic leaves from $E$. necator-infected $V$. Vinifera and the only reaction described so far targeted by dirigent proteins of the DIR-a subfamily (dimerization of coniferyl alcohol to afford (+)-pinoresinol), the transcription levels of the genes whose products operate in the metabolic neighbourhood of coniferyl 
alcohol were analyzed (Fig. 4). The main objective of such an experiment was trying to correlate the expression level of those genes involved in the metabolism of the monolignol with the observed, fungal-induced upregulation of the DIR gene. Even though this analysis is not representative of the extremely intricate cellular metabolism, it may provide clues indicative of major metabolic flux alterations. When the transcription rate of most enzymes depicted in Fig. 4 was determined under the conditions originating 180 fold upregulation of the DIR gene, it was interesting to note that pinoresinol reductase (PRR), described as the enzyme metabolizing the product of the DIR-assisted reaction, undergoes downregulation. Alternative explanations include divergent branching of lignan biosynthetic pathway, in which pinoresinol is converted into metabolites other than lariciresinol, or the involvement of the DIR in the stereochemical control of other reactions.

In the absence of the DIR protein under study, three isomers are formed by dimerization of coniferyl alcohol molecules, in an oxidative reaction which occurs either spontaneously or in the presence of peroxidases [15]: pinoresinol, dehydrodiconiferyl alcohol (DDCA) and guaiacylglycerol 8-O-4'-coniferyl ether (GGCE), in the thermodynamic-dependent, relative proportions of $26-28 \%$, $52-57 \%$ and $17-19 \%$, respectively. In a different study, Halls confirmed similar proportions as $0.5: 1.0: 0.3$. However, only $(+)$-pinoresinol is formed when the DIR protein is present [60]. Furthermore, the complete stereoselectivity is preserved as long as the oxidative capacity does not exceed a point where the DIR protein becomes saturated [15].

Knowing that both DDCA [61] and GGCE [62] have been reported as lignin precursors, a different hypothesis may be formulated to explain the $>180$ fold increase in DIR gene transcription in symptomatic grapevine leaves infected with powdery mildew: to ensure that neither of the two isomers other than (+)-pinoresinol is formed under such conditions. If this hypothesis is correct, a low level of DIR during the initial stages of $E$. necator infection may allow lignin biosynthesis to build up physical barriers, whereas a potent, lignan dependent antifungal activity is considered a host priority at later stages of infection.

\section{Experimental procedures}

\subsection{Plant material and growth conditions}

Grapevine (Vitis vinifera L., cultivar Touriga Nacional) cuttings used in the experiment were collected from Centro Experimental de Pegões, Portugal, and subjected to heartwood disease screening through microbiology assays. The microbiologic screening was performed using the bottom of the cuttings. Thin wood slices were removed from each cutting, surface-sterilized (ethanol, flame and sodium hypochlorite) and then placed in $0.03 \%(\mathrm{w} / \mathrm{v})$ chloramphenicol-containing PDA medium (five slices per cutting). The plates were incubated at room temperature for a maximum period of one month, during which morphological identification of the microorganisms present in the wood was performed. Diseased cuttings were discarded.

Healthy $V$. vinifera cuttings, with three buds each, were rooted in water and then transferred to soil ( $1 \mathrm{~L}$ pot per plant). Plants were maintained in a growth chamber at $25{ }^{\circ} \mathrm{C}$ with a photoperiod of $16 \mathrm{~h}\left(480 \mu \mathrm{mol} \mathrm{m} \mathrm{m}^{-2} \mathrm{~s}^{-1}\right)$. After acclimatization, all plants were simultaneously inoculated with $E$. necator by direct contact with naturally infected grapevine leaves. The primary inoculum was collected from a vineyard in Instituto Superior de Agronomia, Lisbon, Portugal and passed to a set of grapevines in greenhouse which provided the experimental inoculum source. Leaves from the greenhouse plants were used to inoculate all the plants in the growth chamber. Plants were allowed to grow with generalized powdery mildew infection for 30 days prior to sample collection. After the infection stage, fully expanded leaves (fourth and fifth positions from the tip of each shoot) with and without $E$. necator infection symptoms (visible mycelia on the upper leaf surface) were randomly harvested and frozen in liquid nitrogen. Biological replicates for symptomatic (S) and asymptomatic (A) conditions were created by pooling four leaves of each condition per sample. All leaves of each pool were collected from different plants from the same experimental setup.

\subsection{RNA extraction}

Total RNA extraction was performed using the CTAB (hexadecyltrimethyl ammonium bromide) method (Chang et al.), especially suited for high phenolic content material [63]. Leaves were ground in liquid nitrogen, homogenized at $1 \mathrm{~g}$ per $20 \mathrm{~mL}$ in extraction buffer $(2 \%(\mathrm{w} / \mathrm{v})$ CTAB, $2 \%(\mathrm{w} / \mathrm{v})$ polyvinylpolypyrrolidone, $2 \mathrm{M} \mathrm{NaCl}, 100 \mathrm{mM}$ Tris- $\mathrm{HCl}$ pH 8.0, $25 \mathrm{mM}$ ethylenediaminetetraacetic acid (EDTA), $2 \%$ (v/v) $\beta$-mercaptoethanol) and incubated at $65{ }^{\circ} \mathrm{C}$ for $10 \mathrm{~min}$. Samples were extracted twice with one volume of chloroform:isoamylic alcohol $(24: 1, \mathrm{v} / \mathrm{v})$ and centrifuged at $12,000 \mathrm{~g}$ during $30 \mathrm{~min}$. The recovered aqueous phase was supplemented with $1 / 4$ volume of $10 \mathrm{M} \mathrm{LiCl}$ and incubated overnight at $4{ }^{\circ} \mathrm{C}$. RNA was collected by centrifugation at $12,000 \mathrm{~g}, 4^{\circ} \mathrm{C}$ during $20 \mathrm{~min}$, and resupended in $1.5 \mathrm{~mL}$ of prewarmed $\left(37{ }^{\circ} \mathrm{C}\right)$ SSTE buffer $(0.5 \% \mathrm{w} / \mathrm{v}$ sodium dodecyl sulphate (SDS), $1 \mathrm{M} \mathrm{NaCl}, 10 \mathrm{mM}$ Tris- $\mathrm{HCl}$ pH 8.0, 1 mM EDTA). Each sample was divided in two and again extracted with one volume of chloroform:isoamylic alcohol $(24: 1, \mathrm{v} / \mathrm{v})$ followed by centrifugation at $15,000 \mathrm{~g}$ during $10 \mathrm{~min}$. The recovered supernatant was supplemented with 2.5 volumes of ethanol and incubated for $2 \mathrm{~h}$ at $-20^{\circ} \mathrm{C}$. RNA was precipitated by centrifugation at $4{ }^{\circ} \mathrm{C}, 15,000 \mathrm{~g}$ during $30 \mathrm{~min}$. The pellet was washed with $70 \%(\mathrm{v} / \mathrm{v})$ ethanol and resuspended in water. Prior to RT-PCR, samples were treated with RQ1 RNase-Free Dnase (Promega) according to the manufacturer's protocol.

\subsection{Suppression subtractive hybridization libraries}

Each sample, $\mathrm{S}$ and A cDNAs, used to perform SSH was synthesized from $4 \mu \mathrm{g}$ of total RNA, using the BD SMART ${ }^{\mathrm{TM}}$ PCR cDNA Synthesis Kit (Clontech). Following PCR cycle optimization for each sample, both cDNA templates were amplified by LD-PCR through 23 temperature cycles according to the manufacturer's protocol. SSH was performed using the PCR-Select cDNA Subtraction Kit (Clontech) following the manufacturer's instructions. Both $S$ and A samples were used as tester and driver for forward and reverse subtractions, respectively. SSH cDNA pools were cloned and transformed using pCR2.1 vector and TOP10 chemically competent Escherichia coli from TA Cloning Kit (Invitrogen). Transformed cells were plated on LB agar plates containing kanamycin $\left(50 \mu \mathrm{g} \mathrm{mL}^{-1}\right)$ overlaid with X-Gal (40 $\mu \mathrm{L}$ of $\left.40 \mathrm{mg} \mathrm{mL}^{-1}\right)$.

\subsection{Dot-blot library screening}

White colonies from both subtractions were randomly picked from the libraries, transferred to liquid LB $\left(50 \mu \mathrm{g} \mathrm{mL}^{-1}\right.$ kanamycin) in 96-well plates and incubated overnight at $37^{\circ} \mathrm{C}$ with agitation. cDNA inserts from each colony were amplified directly from $1 \mu \mathrm{L}$ of the corresponding liquid culture in a $20 \mu \mathrm{L}$ PCR reaction using the Advantage cDNA PCR Kit \& Polymerase Mix (Clontech). Reaction mixtures were prepared with the primers Nested Primer $1\left(5^{\prime}\right.$ TCGAGCGGCCGCCCGGGCAGGT $3^{\prime}$ ) and Nested Primer 2R (5' AGCGTGGTCGCGGCCGAGGT $3^{\prime}$ ), complementary to the adaptors used in the subtraction process. Thermal cycling was performed 
using the following parameters: initial denaturation step at $94{ }^{\circ} \mathrm{C}$ for $30 \mathrm{~s}, 23$ cycles at $95^{\circ} \mathrm{C}$ for $10 \mathrm{~s}$ and $68^{\circ} \mathrm{C}$ for $3 \mathrm{~min}$. After agarose gel analysis, dot-blot arrays were prepared by spotting each amplified insert in duplicate into separate nylon membranes. Probing of the cDNA arrays was performed as described in DIG High Prime DNA Labeling and Detection Starter Kit II (Roche) using labelled forward and reverse SSH cDNA pools as probes. Clones displaying differential hybridization between forward and reverse probes were interpreted as differentially expressed and selected for insert sequencing.

\subsection{Genomic DNA extraction}

Grapevine leaves ( $1 \mathrm{~cm}^{2}$ per sample) were ground in liquid nitrogen and homogenized in $1.5 \mathrm{~mL}$ tubes containing $300 \mu \mathrm{L}$ of extraction buffer $(0.35 \mathrm{M}$ sorbitol, $0.1 \mathrm{M}$ Tris- $\mathrm{HCl} \mathrm{pH}$ 8.2, $5 \mathrm{mM}$ EDTA, $2 \%(v / v) \beta$-mercaptoethanol). Homogenates were supplemented with $300 \mu \mathrm{L}$ of nuclei lysis buffer $(2 \%$ (m/v) CTAB, $2 \mathrm{M} \mathrm{NaCl}$, $0.2 \mathrm{M}$ Tris- $\mathrm{HCl} \mathrm{pH}$ 7.5, $50 \mathrm{mM}$ EDTA) and $120 \mu \mathrm{L}$ 5\% (w/v) Sarkosil, vigorously shaken and incubated at $65^{\circ} \mathrm{C}$ for $15 \mathrm{~min}$. Samples were extracted with $600 \mu \mathrm{L}$ of chloroform:isoamylic alcohol (24:1) and centrifuged at $12,000 \mathrm{~g}$ during $10 \mathrm{~min}$. Ice-cold isopropanol (0.65 vol.) was added to the recovered aqueous phases and the tubes were gently inverted several times. Nucleic acids were collected through centrifugation at $12,000 \mathrm{~g}$ during $5 \mathrm{~min}$, resuspended in $100 \mu \mathrm{L}$ of RNase containing buffer ( $50 \mathrm{mM}$ Tris- $\mathrm{HCl} \mathrm{pH}$ 8.0, $10 \mathrm{mM}$ EDTA) and incubated for $15 \mathrm{~min}$ at room temperature. Samples were again extracted with chloroform:isoamylic alcohol (24:1) and precipitated with isopropanol. Following $70 \%(\mathrm{v} / \mathrm{v})$ ethanol washing, the pellet was resuspended in $50 \mu \mathrm{L} \mathrm{TE}(10 \mathrm{mM}$ Tris- $\mathrm{HCl}$ pH 8.0, 1 mM EDTA).

\subsection{Real-time $P C R$}

Reverse transcription reactions for gene expression studies were performed using ThermoScript RT-PCR System (Invitrogen) as described by the manufacturer. cDNA was synthesized from $1.5 \mu \mathrm{g}$ of total RNA and oligo $(\mathrm{dT})_{20}$ primed. RT reactions were carried at $55^{\circ} \mathrm{C}$ for $60 \mathrm{~min}$.

All PCR primers were designed with Beacon Designer software (Premier Biosoft International) to target amplicons between 80 and 300 bps. qPCR was performed with iQ SYBR Green supermix (Bio-Rad) using iCycler equipment (Bio-Rad). cDNA for reference gene validation and gene expression studies was diluted to 15$30 \mathrm{ng} / \mu \mathrm{L}$. Genomic DNA to determine DIR copy number was diluted to $10 \mathrm{ng} / \mu \mathrm{L}$. Reaction mixtures $(20 \mu \mathrm{L})$ were prepared according to the following methodology: $1 \mu \mathrm{L}$ of the diluted template, $1 \mu \mathrm{L}$ primer mix (10 $\mu \mathrm{M}$ each), $10 \mu \mathrm{L}$ iQ SYBR Green supermix (Bio-Rad), $8 \mu \mathrm{L} \mathrm{H}_{2} \mathrm{O}$. Thermal cycling was composed of an initial denaturation step for $3 \mathrm{~min}$ at $95^{\circ} \mathrm{C}, 40$ cycles at $95^{\circ} \mathrm{C}$ for $10 \mathrm{~s}, 55^{\circ} \mathrm{C}$ for $30 \mathrm{~s}$ and $72{ }^{\circ} \mathrm{C}$ for $30 \mathrm{~s}$. All reactions were performed in triplicate and amplification specificity was assessed through melting curve analysis.

Reference gene validation was performed using geNorm software to determine which of the candidates were most stable under the experimental conditions. Validation was based on amplification efficiency corrected data referring to normalized quantities of 6 candidate reference genes in 8 biological samples. Following geNorm stability ranking, relative gene expression analysis was performed using $U B C$ and VAG1 as normalization genes. The experiments were carried out using four biological replicates for SSH-detected transcripts and two biological replicates for coniferyl alcohol branching enzymes. All reactions were performed in triplicate and amplification specificity was assessed through melting curve analysis.

\section{Acknowledgements}

The financial assistance of Fundação para a Ciência e a Tecnologia (Lisbon, Portugal) under grant no. SFRH/BD/61903/2009 is gratefully acknowledged. The authors thank Dr. Antero Martins (Instituto Superior de Agronomia, Lisbon, Portugal) for the information on the susceptibility of individual grapevine cultivars to powdery mildew.

\section{References}

[1] D.A. Glawe, The powdery mildews: a review of the world's most familiar (yet poorly known) plant pathogens, Annual Review of Phytopathology 46 (2008) 27-51.

[2] O. Carisse, R. Bacon, A. Lefebvre, Grape powdery mildew (Erysiphe necator) risk assessment based on airborne conidium concentration, Crop Protection 28 (2009) 1036-1044.

[3] R.B. Ferreira, S. Monteiro, R. Freitas, C.N. Santos, Z. Chen, L.M. Batista, J. Duarte, A. Borges, A.R. Teixeira, The role of plant defence proteins in fungal pathogenesis, Molecular Plant Pathology 8 (2007) 677-700.

[4] A. Pitzschke, A. Schikora, H. Hirt, MAPK cascade signalling networks in plant defence, Current Opinion in Plant Biology 12 (2009) 421-426.

[5] J.D.G. Jones, J.L. Dangl, The plant immune system, Nature 444 (2006) 323-329.

[6] V. Nicaise, M. Roux, C. Zipfel, Recent advances in PAMP-triggered immunity against bacteria: pattern recognition receptors watch over and raise the alarm, Plant Physiology 150 (2009) 1638-1647.

[7] S.T. Chisholm, G. Coaker, B. Day, B.J. Staskawicz, Host-microbe interactions: shaping the evolution of the plant immune response, Cell 124 (2006) 803-814.

[8] K. Mendgen, M. Hahn, Plant infection and the establishment of fungal biotrophy, Trends in Plant Science 7 (2002) 352-356.

[9] R. Panstruga, Establishing compatibility between plants and obligate biotrophic pathogens, Current Opinion in Plant Biology 6 (2003) 320-326.

[10] R.J. O'Connell, R. Panstruga, Tete a tete inside a plant cell: establishing compatibility between plants and biotrophic fungi and oomycetes, The New Phytologist 171 (2006) 699-718.

[11] M.G. Mullins, A. Bouquet, L.E. Williams, Biology of the Grapevine, New York, 1992.

[12] R. Fung, W. Qiu, Y. Su, D. Schachtman, K. Huppert, C. Fekete, L. Kovács, Gene expression variation in grapevine species Vitis vinifera $L$. and Vitis aestivalis Michx, Genetic Resources and Crop Evolution 54 (2007) 1541-1553.

[13] R.W.M. Fung, M. Gonzalo, C. Fekete, L.G. Kovacs, Y. He, E. Marsh, L.M. McIntyre, D.P. Schachtman, W. Qiu, Powdery mildew induces defenseoriented reprogramming of the transcriptome in a susceptible but not in a resistant grapevine, Plant Physiology 146 (2008) 236-249.

[14] R.A. Caldo, D. Nettleton, J. Peng, R.P. Wise, Stage-specific suppression of basal defense discriminates barley plants containing fast- and delayed-acting Mla powdery mildew resistance alleles, Molecular Plant-Microbe Interactions 19 (2006) 939-947.

[15] L.B. Davin, H.-B. Wang, A.L. Crowell, D.L. Bedgar, D.M. Martin, S. Sarkanen, N.G. Lewis, Stereoselective bimolecular phenoxy radical coupling by an auxiliary (dirigent) protein without an active center, Science 275 (1997) 362-367.

[16] T. Umezawa, Diversity in lignan biosynthesis, Phytochemistry Reviews 2 (2003) 371-390.

[17] W.D. MacRae, G.H.N. Towers, Biological activities of lignans, Phytochemistry 23 (1984) 1207-1220.

[18] K. Akiyama, M. Maruyama, S. Yamauchi, Y. Nakashima, T. Nakato, R. Tago, T. Sugahara, T. Kishida, Y. Koba, Antimicrobiological activity of lignan: effect of benzylic oxygen and stereochemistry of 2,3-dibenzyl-4-butanolide and 3,4dibenzyltetrahydrofuran lignans on activity, Bioscience, Biotechnology, and Biochemistry 71 (2007) 1745-1751.

[19] S. Ralph, J.-Y. Park, J. Bohlmann, S. Mansfield, Dirigent proteins in conifer defense: gene discovery, phylogeny, and differential wound- and insectinduced expression of a family of DIR and DIR-like genes in spruce (Picea spp.), Plant Molecular Biology 60 (2006) 21-40.

[20] J. Liu, R.D. Stipanovic, A.A. Bell, L.S. Puckhaber, C.W. Magill, Stereoselective coupling of hemigossypol to form (+)-gossypol in moco cotton is mediated by a dirigent protein, Phytochemistry 69 (2008) 3038-3042.

[21] V. Burlat, M. Kwon, L.B. Davin, N.G. Lewis, Dirigent proteins and dirigent sites in lignifying tissues, Phytochemistry 57 (2001) 883-897.

[22] K. Reid, N. Olsson, J. Schlosser, F. Peng, S. Lund, An optimized grapevine RNA isolation procedure and statistical determination of reference genes for realtime RT-PCR during berry development, BMC Plant Biology 6 (2006) 27.

[23] N. Nicot, J.-F. Hausman, L. Hoffmann, D. Evers, Housekeeping gene selection for real-time RT-PCR normalization in potato during biotic and abiotic stress, Journal of Experimental Botany 56 (2005) 2907-2914.

[24] T. Gjetting, T.L. Carver, L. Skot, M.F. Lyngkjaer, Differential gene expression in individual papilla-resistant and powdery mildew-infected barley epidermal cells, Molecular Plant-Microbe Interactions: MPMI 17 (2004) 729-738.

[25] J. Vandesompele, K. De Preter, F. Pattyn, B. Poppe, N. Van Roy, A. De Paepe, F. Speleman, Accurate normalization of real-time quantitative RT-PCR data by 
geometric averaging of multiple internal control genes, Genome Biology 3 (2002). research0034.0031-research0034.0011.

[26] S.G. Ralph, S. Jancsik, J. Bohlmann, Dirigent proteins in conifer defense II: extended gene discovery, phylogeny, and constitutive and stress-induced gene expression in spruce (Picea spp.), Phytochemistry 68 (2007) 1975-1991.

[27] M. Kanehisa, S. Goto, KEGG: Kyoto encyclopedia of genes and genomes, Nucleic Acids Research 28 (2000) 27-30.

[28] M. Kanehisa, S. Goto, Y. Sato, M. Furumichi, M. Tanabe, KEGG for integration and interpretation of large-scale molecular data sets, Nucleic Acids Research 40 (2012) D109-D114.

[29] P.-P. Liu, S. Bhattacharjee, D.F. Klessig, P. Moffett, Systemic acquired resistance is induced by $\mathrm{R}$ gene-mediated responses independent of cell death, Molecular Plant Pathology 11 (2010) 155-160.

[30] T.E. Mishina, J. Zeier, Pathogen-associated molecular pattern recognition rather than development of tissue necrosis contributes to bacterial induction of systemic acquired resistance in Arabidopsis, The Plant Journal 50 (2007) 500-513.

[31] A.C. Vlot, D.F. Klessig, S.-W. Park, Systemic acquired resistance: the elusive signal(s), Current Opinion in Plant Biology 11 (2008) 436-442.

[32] K. Tsuda, F. Katagiri, Comparing signaling mechanisms engaged in patterntriggered and effector-triggered immunity, Current Opinion in Plant Biology 13 (2010) 459-465.

[33] M. Xu, B. Zhang, X. Su, S. Zhang, M. Huang, Reference gene selection for quantitative real-time polymerase chain reaction in Populus, Analytical Biochemistry 408 (2011) 337-339.

[34] T. Løvdal, C. Lillo, Reference gene selection for quantitative real-time PCR normalization in tomato subjected to nitrogen, cold, and light stress, Analytical Biochemistry 387 (2009) 238-242.

[35] G. Wu, L. Zhang, Y. Wu, Y. Cao, C. Lu, Comparison of five endogenous reference genes for specific PCR detection and quantification of Brassica napus, Journal of Agricultural and Food Chemistry 58 (2010) 2812-2817.

[36] M. Jain, A. Nijhawan, A.K. Tyagi, J.P. Khurana, Validation of housekeeping genes as internal control for studying gene expression in rice by quantitative real-time PCR, Biochemical and Biophysical Research Communications 345 (2006) 646-651.

[37] R. Hückelhoven, Powdery mildew susceptibility and biotrophic infection strategies, FEMS Microbiology Letters 245 (2005) 9-17.

[38] S.M. Schmidt, R. Panstruga, Cytoskeleton functions in plant-microbe interactions, Physiological and Molecular Plant Pathology 71 (2008) 135-148.

[39] S. Derveaux, J. Vandesompele, J. Hellemans, How to do successful gene expression analysis using real-time PCR, Methods 50 (2010) 227-230.

[40] C. Fekete, R.W.M. Fung, Z. Szabó, W. Qiu, L. Chang, D.P. Schachtman, L.G. Kovács, Up-regulated transcripts in a compatible powdery mildewgrapevine interaction, Plant Physiology and Biochemistry 47 (2009) 732-738.

[41] S.C. Venugopal, B. Chanda, L. Vaillancourt, A. Kachroo, P. Kachroo, The common metabolite glycerol-3-phosphate is a novel regulator of plant defense signaling, Plant Signaling \& Behavior 4 (2009) 746-749.

[42] T. Shigaki, M.K. Bhattacharyya, Decreased inositol 1,4,5-trisphosphate content in pathogen-challenged soybean cells, Molecular Plant-Microbe Interactions 13 (2000) 563-567.

[43] J. Zhao, L.C. Davis, R. Verpoorte, Elicitor signal transduction leading to production of plant secondary metabolites, Biotechnology Advances 23 (2005) 283-333.

[44] P.H. Meng, C. Raynaud, G. Tcherkez, S. Blanchet, K. Massoud, S. Domenichini, Y. Henry, L. Soubigou-Taconnat, C. Lelarge-Trouverie, P. Saindrenan, J.P. Renou, C. Bergounioux, Crosstalks between myo-inositol metabolism, programmed cell death and basal immunity in Arabidopsis, PLoS ONE 4 (2009) e7364.

[45] P. Schäfer, S. Pfiffi, L.M. Voll, D. Zajic, P.M. Chandler, F. Waller, U. Scholz, J. Pons-Kühnemann, S. Sonnewald, U. Sonnewald, K.-H. Kogel, Manipulation of plant innate immunity and gibberellin as factor of compatibility in the mutualistic association of barley roots with Piriformospora indica, The Plant Journal 59 (2009) 461-474.

[46] M. Petersen, P. Brodersen, H. Naested, E. Andreasson, U. Lindhart, B. Johansen, H.B. Nielsen, M. Lacy, M.J. Austin, J.E. Parker, S.B. Sharma, D.F. Klessig, R. Martienssen, O. Mattsson, A.B. Jensen, J. Mundy, Arabidopsis MAP kinase 4 negatively regulates systemic acquired resistance, Cell 103 (2000) 11111120.

[47] V. Lauvergeat, C. Lacomme, E. Lacombe, E. Lasserre, D. Roby, J. Grima-Pettenati, Two cinnamoyl-CoA reductase (CCR) genes from Arabidopsis thaliana are differentially expressed during development and in response to infection with pathogenic bacteria, Phytochemistry 57 (2001) 1187-1195.

[48] L.L. Escamilla-Trevino, H. Shen, S.R. Uppalapati, T. Ray, Y.H. Tang, T. Hernandez, Y.B. Yin, Y. Xu, R.A. Dixon, Switchgrass (Panicum virgatum) possesses a divergent family of cinnamoyl CoA reductases with distinct biochemical properties, The New Phytologist 185 (2010) 143-155.

[49] H.A. So, E. Chung, C.W. Cho, K.Y. Kim, J.H. Lee, Molecular cloning and characterization of soybean cinnamoyl CoA reductase induced by abiotic stresses, Plant Pathology Journal 26 (2010) 380-385.

[50] X. Tang, M. Xie, Y.J. Kim, J. Zhou, D.F. Klessig, G.B. Martin, Overexpression of Pto activates defense responses and confers broad resistance, Plant Cell 11 (1999) 15-29.

[51] T. Kawasaki, H. Koita, T. Nakatsubo, K. Hasegawa, K. Wakabayashi, H. Takahashi, K. Urnemura, T. Urnezawa, K. Shimamoto, Cinnamoyl-CoA reductase, a key enzyme in lignin biosynthesis, is an effector of small GTPase Rac in defense signaling in rice, Proceedings of the National Academy of Sciences of the United States of America 103 (2006) 230-235.

[52] H. Hayashi, P. Huang, S. Takada, M. Obinata, K. Inoue, M. Shibuya, Y. Ebizuka Differential expression of three oxidosqualene cyclase mRNAs in Glycyrrhiza glabra, Biological \& Pharmaceutical Bulletin 27 (2004) 1086-1092.

[53] A.E. Osbourn, Saponins in cereals, Phytochemistry 62 (2003) 1-4.

[54] X. Chang, E. Heene, F. Qiao, P. Nick, The phytoalexin resveratrol regulates the initiation of hypersensitive cell death in Vitis cell, PLoS ONE 6 (2011) e26405.

[55] S. Schnee, O. Viret, K. Gindro, Role of stilbenes in the resistance of grapevine to powdery mildew, Physiological and Molecular Plant Pathology 72 (2008) $128-133$.

[56] L. Schmidlin, A. Poutaraud, P. Claudel, P. Mestre, E. Prado, M. Santos-Rosa, S. Wiedemann-Merdinoglu, F. Karst, D. Merdinoglu, P. Hugueney, A stressinducible resveratrol O-methyltransferase involved in the biosynthesis of pterostilbene in grapevine, Plant Physiology 148 (2008) 1630-1639.

[57] S. Apers, A. Vlietinck, L. Pieters, Lignans and neolignans as lead compounds, Phytochemistry Reviews 2 (2003) 201-217.

[58] M. Saleem, H.J. Kim, M.S. Ali, Y.S. Lee, An update on bioactive plant lignans, Natural Product Reports 22 (2005) 696-716.

[59] L. Zhu, X. Zhang, L. Tu, F. Zeng, Y. Nie, X. Guo, Isolation and characterization of two novel dirigent-like genes highly induced in cotton (Gossypium barbadense and G. hirsutum) after infection by Verticillium dahliae, Journal of Plant Pathology 89 (2007) 41-45.

[60] S.C. Halls, L.B. Davin, D.M. Kramer, N.G. Lewis, Kinetic study of coniferyl alcohol radical binding to the $(+)$-pinoresinol forming dirigent protein, Biochemistry 43 (2004) 2587-2595.

[61] H. Takeda, T. Kotake, N. Nakagawa, N. Sakurai, D.J. Nevins, Expression and function of cell wall-bound cationic peroxidase in asparagus somatic embryogenesis, Plant Physiology 131 (2003) 1765-1774.

[62] F.F. Nord, The formation of lignin and its biochemical degradation, Geochimica et Cosmochimica Acta 28 (1964) 1507-1522.

[63] S. Chang, J. Puryear, J. Cairney, A simple and efficient method for isolating RNA from pine trees, Plant Molecular Biology Reporter 11 (1993) 113-116. 